\title{
Eph signaling is required for segmentation and differentiation of the somites
}

\author{
Lindsey Durbin, ${ }^{1}$ Caroline Brennan, ${ }^{1}$ Kensuke Shiomi, Julie Cooke, Arantza Barrios, \\ Shantha Shanmugalingam, Brenda Guthrie, ${ }^{3}$ Rick Lindberg $^{2}$ and Nigel Holder ${ }^{3}$
}

Department of A natomy and Developmental Biology, University College, London, WC1E 6BT, UK; ${ }^{2}$ Amgen Center, Thousand Oaks, California 91320 USA

\begin{abstract}
Somitogenesis involves the segmentation of the paraxial mesoderm into units along the anteroposterior axis. Here we show a role for Eph and ephrin signaling in the patterning of presomitic mesoderm and formation of the somites. Ephrin-A-L1 and ephrin-B2 are expressed in an iterative manner in the developing somites and presomitic mesoderm, as is the Eph receptor EphA4. We have examined the role of these proteins by injection of RNA, encoding dominant negative forms of Eph receptors and ephrins. Intermuption of Eph signal ing leads to abnormal somite boundary formation and reduced or disturbed myoD expression in the myotome. Disnuption of Eph family signaling delays the normal down-regulation of her1 and D elta D expression in the anterior presomitic mesoderm and disrupts myogenic differentiation. We suggest that Eph signaling has a key role in the translation of the patteming of presomitic mesoderm into somites.
\end{abstract}

[Key Words: Somitogenesis; Eph/ephrin signaling; zebrafish]

Received March 5, 1998; revised version accepted July 10, 1998.

The subdivision of paraxial mesoderm into somites is the initial mesodermal segmentation event of vertebrate development. The formation and differentiation of somites is the result of three distinct processes: prepatterning of the mesoderm, boundary formation, and patterning within the somiteitself. Several lines of evidence suggest that the presomitic mesoderm is prepatterned into metameric subunits (Gossler and Hrabe de Angelis 1998). Recently, molecular evidence for segmental subdivision of the presomitic mesoderm has been obtained. The basic helix-loop-helix (bHLH) transcription factors her 1 and c-hairy-1 are expressed dynamically in the presegmental somitic plate of zebrafish and chick, respectively (Muller et al. 1996; Palmeirim et al. 1997). Their expression patterns suggest that these genes function in the establishment of a segmental pattern within this region of the embryo, although it is not clear at this stage whether these genes function in the same way. The transcription factor MesP2 is also required for normal segmentation (Saga et al. 1997). The second process of somite development involves the translation of the segmental prepattern into the morphogenetic changes that accompany formation of the somite boundaries. Recently a number of studies have shown that $\mathrm{N}$ otchDelta intercellular signaling is involved in boundary for-

\footnotetext{
${ }^{1}$ These authors contributed equally to the work.

${ }^{3}$ Corresponding author.

E-MAIL N.Holder@ucl.ac.uk; FAX 0171-504-2091.
}

mation; al tering the function of $\mathrm{N}$ otch or Delta by loss and gain of function leads to abnormal somite formation. Finally, the somites themsel ves are patterned and differentiation events take place (Gossler and Hrabe de Angelis 1998).

Intercellular signaling is one of the processes that underlies segmentation in vertebrate embryos. The Eph family of receptor tyrosine kinases are cell surface molecules shown to have a role in intercellular signaling and patterning of the neural tube (Gale and Yancopoulos 1997). Several Eph receptors and ephrins are expressed in the somites (Bergemann et al. 1995; Scales et al. 1995; Flenniken et al. 1996; Gale et al. 1996; Cooke et al. 1997). Ephrins can be divided into two classes according to their method of membrane attachment; class A ephrins have a glycosyl-phosphotidyl-inositol (GPI) linkage and class B ephrins are transmembrane proteins capable of transducing a signal into the expressing cell (Holland et al. 1996; Bruckner et al. 1997). Eph receptors can al so be divided into two classes according to their binding preferences such that EphA receptors bind class A ephrins, whereas EphB receptors recognize class B ephrins. Several groups have demonstrated that in vitro binding within these classes is promiscuous and any class A receptor can bind any class A ephrin (Brambilla et al. 1995; Gale et al. 1996). U sing injections of RNA encoding fulllength or truncated forms of EphA4 into zebrafish eggs we have demonstrated a role for the Eph family in hindbrain segmentation and forebrain patterning ( $\mathrm{Xu}$ et al. 
1995, 1996). A similar approach has been used to demonstrate the role of the Eph family in neural crest migration in Xenopus (Smith et al. 1997). As binding is promiscuous between different members of the same subclass, high level ectopic expression of a dominant negative form of a class $A$ protein would be expected to interfere with signaling to all class $A$ receptors. This could be achieved by the ability of the dominant negative receptor to bind to endogenous type A ligands, preventing them from binding to endogenous receptor, or by heterodimerization. As soluble forms of ephrins can bind receptors but do not cause activation, these act as receptor antagonists (Krull et al. 1997). Thus, injection of RN A to encode dominant negative forms of a class $A$ and class $B$ receptor and a soluble class $A$ and class $B$ ephrin will give an indication of the role of the Eph family in any particular developmental process.

We have isol ated a class A ligand of uncertain homology, ephrin-A-L1, and ephrin-B2 in zebrafish and we demonstrate here their expression in the somites. We injected RNA encoding soluble forms of these ligands and dominant negative forms of the class $A$ receptor EphA 4 and a class B receptor of uncertain homol ogy EphB-rtk8 (Cooke et al. 1997) to investigate the role of the Eph family in somite development. We show that disruption of Eph signaling results in the abnormal formation of somite boundaries.

\section{Results}

Cloning of zebrafish ephrin class A ligand L1, ephrin-B2, and Eph class B receptor rtk8

Fragments of the two ligands ephrin-A-L1 and ephrin-B2 were isolated by PCR amplification of a zebrafish neurula stage cDN A library. The degenerate primers used for the PCR were complimentary to conserved regions within ephrin-A1 (Bartley et al. 1994) and ephrin-A5 (Winslow et al. 1995) for ephrin-A-L1, and ephrin-B2 (Bergemann et al. 1995) and ephrin-B1 (Fletcher et al. 1994) for ephrin-B2. cDN As containing complete open reading frames were isol ated for these ephrins by screening the neurula stage CDNA library with the PCR fragments. Sequence comparisons showed both ephrin-A-L1 and ephrin-B2 to contain the four conserved cysteine residues in the putative receptor-binding region characteristic of the ephrin family. Ephrin-A-L1 al so has a GPI linkage signal indicating that this is a class $A$ ephrin, and ephrin-B2 has a transmembrane domain showing that this is a class B ephrin (Fig. 1). Ephrin-A-L1 is not necessarily the orthol og of any higher vertebrate ephrin, but it shows most homology to ephrin-A 1 (59\% similar and $48 \%$ identical at the amino acid level). Zebrafish ephrinB2 is $66 \%$ identical to and $83 \%$ similar to mouse ephrinB2 at the amino acid level.

The full-length EphB-rtk8 coding region was isolated by screening a zebrafish 3-15 hr cDNA library with a fragment from a previously isolated EphB-rtk8 partial cDNA (Cooke et al. 1997; Fig. 1). It is not possible to determine the higher vertebrate ortholog of EphB-rtk8, although it shows greatest homology to EphB4 (60\% identical and $70 \%$ similar at the amino acid level).

Ephrin-A-L1, ephrin-B2, and EphA4 are expressed in the somites as they form

The expression patterns of ephrin-A-L1 and ephrin-B2 were investigated by in situ hybridization, and both are expressed in the somites as they are formed (Fig. 2). Ephrin-B2 expression is first seen in the germ ring of $30 \%-$ $60 \%$ epiboly embryos (Fig. 2A). In bud stage embryos ephrin-B2 transcripts are detected in three stripes in the paraxial mesoderm, and in a stripe in the presumptive hindbrain (Fig. 2B), and other regions of the anterior neural plate (data not shown). At the two-somite stage four stripes of ephrin-B2 expression are seen in the paraxial mesoderm, two of which are in the presomitic mesoderm (Fig. 2C), and in the tail bud. By six somites, ephrinB2 is expressed in the posterior region of the formed somites and in two or three stripes in the rostral presomitic mesoderm. These presomitic expression domains correspond to posterior domains of the most rostral presumptive somites (Fig. 2D). As the somites differentiate, the anteroposterior restriction of ephrin-B2 expression is lost, and ephrin-B2 is found in a lateral domain. From 16 somites ephrin-B2 expression is further restricted to dorsal and ventral lateral regions within the most anterior somites. From 24 somites loss of ephrinB2 expression is initiated in an anterior to posterior wave. By prim-5 (24 hr after fertilization) only the most posterior somites still express ephrin-B2.

Expression of ephrin-A-L1 is first seen at $60 \%-70 \%$ epiboly in the epibolizing margin and in the hypoblast. Expression is higher on the ventral than the dorsal side of the embryo (Fig. 2E). At 90\%-100\% epiboly ephrin-A-L1 is still detected around the margin with stronger expression on the dorsal side in the presumptive tailbud and with weak expression in cells on either side of the presumptive notochord (Fig. 2F). Between the one- and fivesomite stages ephrin-A-L 1 transcripts are detected in the tailbud and adaxial cells and weakly in stripes in the somitic mesoderm and throughout the most rostral presomitic mesoderm (Fig. 2G). During these stages ephrinA-L1 expression is also detected in individual paired cells in the neural tube and around the pillow. From the six-somite stage ephrin-A-L1 is expressed more strongly in the posterior region of the formed somites (Fig. $2 \mathrm{H}$ ). After the completion of somitogenesis ephrin-A-L1 expression is lost progressively in an anterior-to-posterior wave in a similar fashion to that seen with ephrin-B2.

Because several members of the Eph family in zebrafish and other species are expressed in the somites we investigated the expression of the other known zebrafish members of the Eph family in the somites and the presomitic mesoderm. The expression of three other Eph ligands (ephrin-A-L2, ephrin-A-L3, and ephrin-A-L4; Brennan et al. 1997; Macdonald et al. 1997) and nine receptors (Eph-rtk 1-8, and EphA-Zdk; Xu et al. 1994; Taneja et al. 1996; Cooke et al. 1997) was determined by in situ hybridization during gastrula and somite stages. 
A ephrin-A-L

B zebrafish ephrin-B2 mouse ephrin-82 human ephrin-B2 zebrafish ephrin-B2 mouse ephrin-B2 human ephrin-B2 zebrafish ephrin-B2 mouse ephrin-B2 human ephrin-B2 zebrafish ephrin-B2 mouse ephrin-B2 human ephrin-B2 zebrafish ephrin-B2 mouse ephrin-B2 human ephrin-B2

zebrafish ephrin-B2 mouse ephrin-B2 human ephrin- $\mathrm{B} 2$

zebrafish ephrin-B2 mouse ephrin-B2 human ephrin-B2

C EphB-rtk 8

Figure 1. (A) Amino acid sequence of zebrafish ephrin-A-L1. (B) Alignment of the protein sequences of zebrafish ephrin-B2 with mouse and human ephrin-B2. Identical residues shown by shading. (C) Amino acid sequence of zebrafish EphB-rtk8. Signal sequences are underlined; probable transmembrane domains are double underlined; putative GPI linkage signal is overlined; conserved cysteine residues are boxed.
1 MDFLWLLCVA VSVSAWYASA ERHSVYWNST NANFLWDDYT VDVRINDYLD 50 51 ITCHYAHGE TASOEAERYV LYMVELEDYE NCKPHSEDOL RWECSRPFAP 100 101 HAPEKFSEKF QRFTPFTLGK EFRQGESYYY ISKPLHHHGQ ECLLLKVDVV 150 151 GPHGSKNKKK MVEKVEEIEG KMAAGGVHNP SNRLPADDPI AMIPVVQRSV 200 201 GSSGVSVAPI SSFVTLLSVF ICLVLHQAS

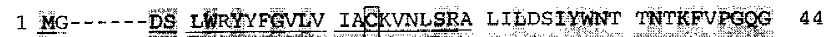

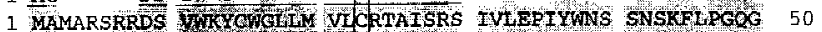

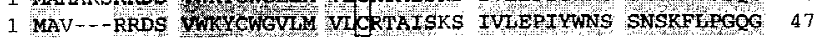

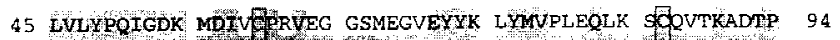

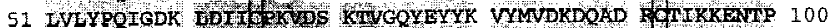

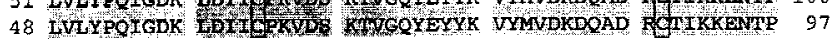

95 MNGVKPDOD VKFTLKOQRP SPNGGLEFF RGKDYYIIST SNGTMEGLDN 144 101 ILINARPDOD VRFIMTOEF SPNWWGLEFO KNKDYYIIST SWGSLEGLDN 150

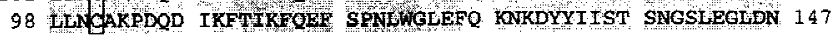

145 QEGGVOKTKS WKIIMKWGON PSDPIGPKDY -PTSYPPKHP DLGGKDSKSA 193 151 OEGGWOTRA MRIMUYOO ALSAGSARNH GPTRRPELEA GTWGRSSTS 200

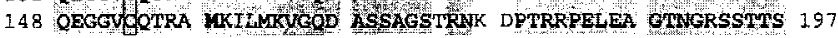

194 EVLKPDASPH GEDKGDGNKS SSVIGSEVAL FACIASASVI VIIIITMLVF 243 201 PFVK PNPGSS TDGNSAGHSE NULOSEVAL FAGTASGCII FIVITITLVV 250 198 PFVKNARGS TDGNSAGHSO MULOSEVAI EAGIASGCII FIXIITHY 247

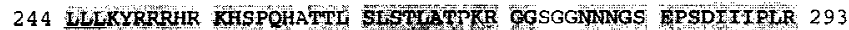

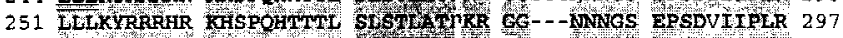

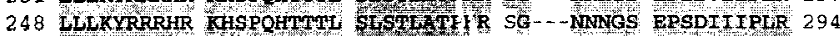

294 TADSVFCHY EKVSGDYGHP VYTVOAMPRO SPANTYYKV

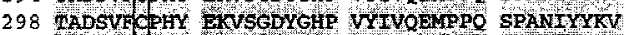

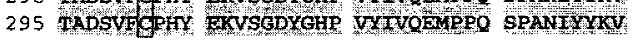

1 MDRVCWIMAL SWFWMVSTGL VSAEEEVLMN TKLETSDLRW TIYPSGDPEW 50 51 EEMSGLDEEG NSVRTFOVCP MDSSVSHWLR TRFIPRHGAS QVYVEIRFTM 100 101 MECSSAMPASF RTCKETFNLY YYQSDEDTAS ATHPAWMENP YSKVDTVAAD 150 151 FLLRRGGERK SNVKTVRVGP LSLFGFYLAF QTQGACMALL SVRVFFKACP 200 201 AVSRAFSSFP ETLPHSLVQQ AEGVCVDNSA PTGOCTAPPT MFCGEDGQWV 250 251 GPPSSTCACK PGYEPVDSDR CRACGLGQYK ASVGGSLCRV CPDNSNTHSA 300 301 GSSLCVCRPG YHRATSDLPD SACTKPPSAF RSIIYQINDT VVTLEWSEPL 350 351 DRGGRSDLSY SVECMICRGS LCVOCADSIT YRPGQMGVSG RRVIIRGLLP 400 401 HTTYTFTVLA QNGVSAVSHT SPASSSVNIT TSRDVAVPVS GIRRIKASES 450 451 SVSISWTVPF OTOHSIODYO LRYSLKGODD GWOYVSSRSS SVVLNDLSRA 500 501 SQYQVQVRAR TAAGYGHFSS AVSISTLPDD EESPSRLMLT GVLVAIGLLI 550 551 LIAVVIVAVE CFRRSTRRRD PDPDKSGQFL MGQGIKVYID PFTYEDPNEA 500 601 VREFAKEIDV SFVKIEEVIG AGEFGEVCRG RLKVFGKKEN YVAIKTLKGG 650 651 YTDKORRDFL SEASIMGOFO HPNIIHLEGV ITASCPVMIL TEYMENGALD 700 701 SFLRLNDGQF TPIQLVGMLR. GIASGMKYLS EMSFVHRDLA ARNILVNSNL 750 751 VCKVSDFGLS RFLTENSSDP TYTSSLGGKI PIRWTAPEAI AFRKFTSASD 800 801 VWSYGIVMWE VMSFGERPYW DMSNODVINA IEQDYRLPPP PECPASLHOL 850 851 MLDCWOKERS SRPRFCAIVS ALDRLIRNPA SLKITGRIPD GPSHPLIDOR 900 901 APPPLSHCSS VADWLRAIKM ERYEDAFMQA GFTAIQHITH ISTEDELRIG 950 951 VTLAGHQKKI LSSVQTLRIH GGSLRY

Of the receptors examined only EphA 4 expression is detected in the presomitic mesoderm and forming somites throughout somitogenesis. Transcripts for EphA4 are first detected in the region of the somites in one-somite stage embryos. At this stage a stripe of expression in a position corresponding to the somite boundary is seen (Fig. 2I). In three-somite embryos four or five stripes of EphA4 expression can be detected in the presomitic and somitic mesoderm. The most posterior of these expression domains corresponds to anterior domains within the anterior presumptive somites (Fig. 2J and Fig. 7A, below). The other stripes of expression correspond to domains in the anterior of the somites that have already formed. EphA 4 is strongly expressed in the adaxial cells during early somite stages, and is detected throughout the posterior paraxial mesoderm.
Of the nine receptors and five ligands studied only ephrin-A-L1, ephrin-B2, and EphA4 were detected in a segmental pattern in the presomitic mesoderm. The spatially restricted expression of these genes within the presomitic mesoderm is suggestive of a role in somite formation. The expression of ephrin-B2 and EphA4 in the presomitic mesoderm is indicative of an anteroposterior prepattern within the presumptive somite.

Ephrin-B2 binds to EphB-rtk8 and EphA4, whereas ephrin-A-L1 binds to EphA 4 but not EphB-rtk8

Before functional studies we assessed the binding characteristics of ephrin-A-L1, ephrin-B2, and EphA4. Fusions of Eph family members with alkal ine phosphatase (AP) were used to investigate the binding of these pro- 


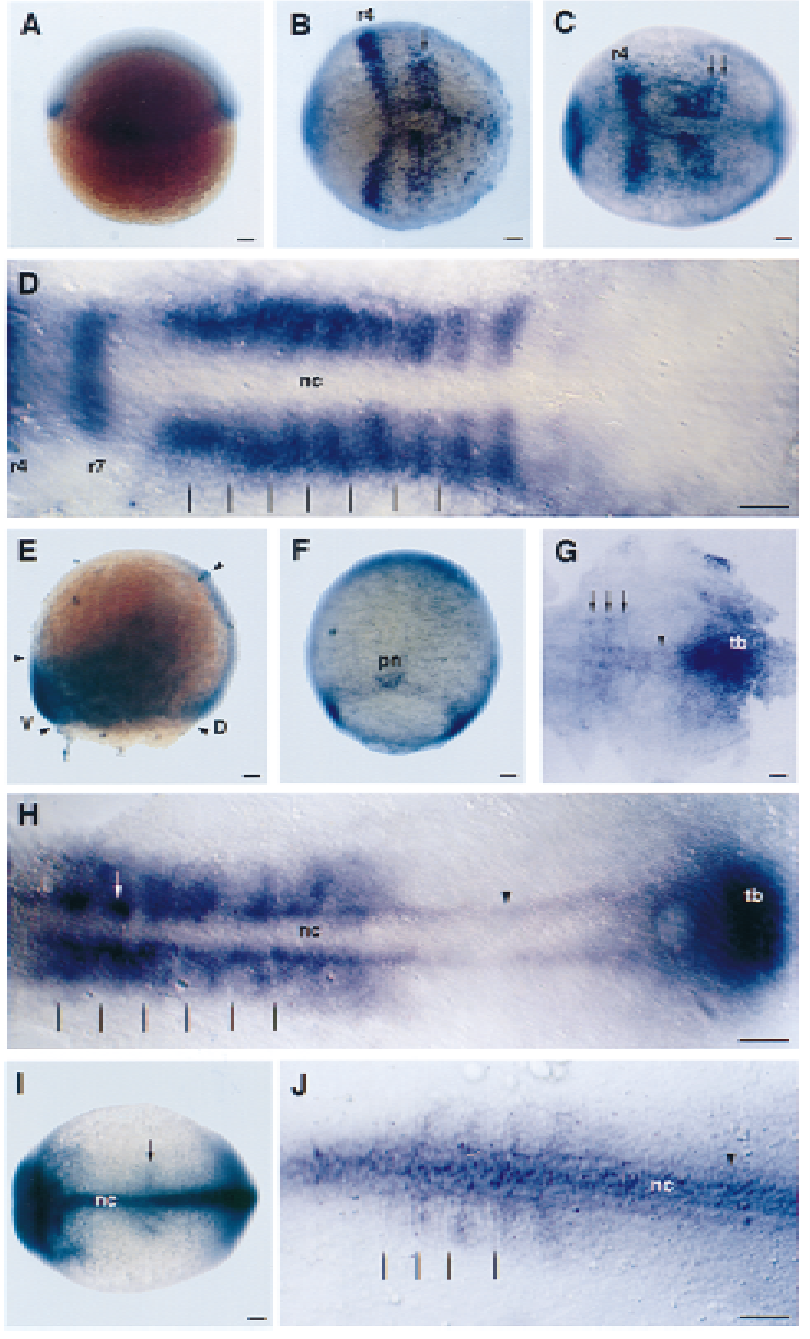

teins in vitro in cell culture and in embryos. Ephrin-AL1-AP bound to Cos cells transfected with EphA4, but did not bind to cells transfected with EphB-rtk8 (Fig. $3 A, B)$. Ephrin-B2-AP bound to cells transfected with either EphB-rtk8 or EphA4 (Fig. 3C,D), a result consistent with the binding characteristics of mouse EphA4, which has been shown previously to bind to $B$ class as well as $A$ class ephrins (Gale et al. 1996). Both EphA4 and EphBrtk8 are capable of binding to ephrin-B2, which is strongly expressed in the presumptive somites from as early as $100 \%$ epiboly. Overexpression of dominant negative constructs of either of these genes would be expected to interfere with ephrin-B2 function in this area of the embryo. EphA4 but not EphB-rtk8 is capable of binding to ephrin-A-L1 and dominant negative forms of EphA4 would also interfere with signaling mediated through this ligand.

Because of the promiscuity of binding shown by members of the Eph family, AP fusion proteins used on embryos find all unbound receptor or ligand molecules of the appropriate class (Gale et al. 1996). To determine whether ligands bound to domains in which no known
Figure 2. Expression of ephrin-B2 (A-D), ephrin-A-L1 $(E-H)$, and EphA4 $(I, J)$. Embryos were hybridized with digoxigenin-label ed antisense RN A probes. Dorsal views (except E lateral view), anterior is to the left (except in A, E,F where anterior is to the top). ephrinB2 expression. (A) 50\% epiboly. Transcripts are detected around the germ ring. (B) Bud stage. Expression is seen in presumptive rhombomere 4 and in three stripes in the presomitic mesoderm (arrow). (C) Two somites. Transcripts are detected in rhombomere 4, in the somites, and in two stripes in the anterior presomitic mesoderm (arrows). (D) Six somites. Expression is seen in rhombomeres 4 and 7, in a posterior domain of the formed somites and in a posterior domain of the most anterior presumptive somites (lines mark the somite boundaries). ephrin-B2 expression is restricted to a lateral domain within the somites as these mature. Ephrin-A-L1 expression. (E) $70 \%$ epiboly. Transcripts are detected in the epibolizing margin and the hypoblast, expression is stronger on the ventral side of the embryo (arrowheads mark the edges of the expression domain). (F) $90 \%$ epiboly. Expression is seen in the epibolizing margin, more strongly around the tailbud, and in cells on either side of the presumptive notochord. (G) One somite. Transcripts are detected in the tailbud, adaxial cells (arrowhead), and in three weak stripes in the formed somite and anterior presomitic mesoderm (arrows). (H) Six somites. Expression is seen in the tailbud and adaxial cells (arrowhead). Ephrin-A-L1 is expressed throughout the somites and anterior presomitic mesoderm, more strongly in the posterior region of each segment (lines mark the somite boundaries). Transcripts are al so detected in individual paired cells in the neural tube (white arrow). EphA4 expression. (I) One somite. Transcripts are detected in the notochord and adaxial cells, and in one stripe in the formed somite (arrow). ()) Three somites. Expression is seen in the notochord and adaxial cells (arrowhead), and in an anterior domain of the somites and most anterior presumptive somites (lines mark the somite boundaries). (D) dorsal; (nc) notochord; (pn) presumptive notochord; (r) rhombomere; (tb) tail bud; (V) ventral; Bars, $100 \mu \mathrm{m}$.

receptors are expressed, or vice versa, we determined the in situ pattern of representative AP fusion proteins for each ligand and receptor class. The class B receptor AP protein (EphB-rtk8-AP) gave a binding pattern within the somites with similar temporal and spatial characteristics as ephrin-B2 expression (Fig. 3G). The class A receptor-AP (EphA-rtk6-AP) gave a binding pattern within the presomitic mesoderm and somites of $95 \%$ epiboly to six-somite stage embryos with similar onset and spatial characteristics as ephrin-A-L1 expression (Fig. 3E,F). N either the class A (ephrin-A-L4-AP, ephrinA-L3-AP, or ephrin-A-L1-AP) nor the class B (ephrin-B2$A P)$ ligand AP fusion proteins show any binding in the somites above background levels, despite giving specific binding patterns in other regions of the embryo consistent with the known expression profiles of Eph family receptors. It would be predicted from in vitro-binding studies that both the class A and B ephrin-AP proteins would recognize and bind to any available EphA 4 in the forming somites. However, the expression of EphA4 in this region is much weaker than in the axial mesoderm or neuroectoderm (Fig. $2 \mathrm{l}, \mathrm{J}$ ), and also weaker than the 


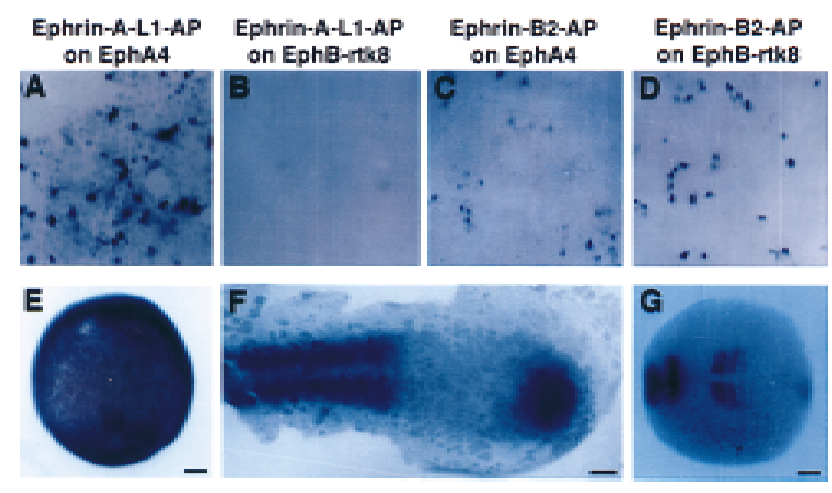

Figure 3. Analysis of the binding characteristics of Eph family proteins in vitro and in situ using alkaline phosphatase-tagged proteins. (A-D) The in vitro binding characteristics of ephrin$A-L 1(A, B)$ and ephrin-B2 (C,D). Ephrin-B2-AP and ephrin-AL1-AP were put on Cos cells that had been transfected with EphA4 $(A, C)$ or EphB-rtk8 (B,D). Staining of cells indicates that theligand binds to the expressed receptor. Both ephrin-A-L1 and ephrin-B2 can bind to EphA4 $(A, C)$, but only ephrin-B2 can bind to EphB-rtk8 $(B, D)$. The presence of class $A$ and $B$ ephrins within the somites was investigated in situ using an AP-tagged protein representative for each of the receptor classes. Dorsal views, anterior is to the left (except in $\mathrm{E}$ where anterior is to the top). EphA-rtk6-AP binding to $95 \%$ epiboly (E) and six-somite (F) embryos is shown, and EphB-rtk8-AP binding to two somite embryos (G). The resulting binding patterns look very similar to the expression patterns of ephrin-A-L1 and ephrin-B2, respectively, at comparable stages (Fig. 2C,F,H). Bars, $100 \mu \mathrm{m}$.

expression levels of ephrin-B2 and ephrin-A-L1 in the paraxial mesoderm, making detection difficult. Protein levels could also be relatively low, leaving little free receptor once it has interacted with its endogenous ligands. It is also possible that endogenous alkaline phosphatase activity, which is particularly difficult to eliminate from within the presomitic mesoderm and somites compared to other regions of the embryo, prevents the detection of low levels of protein in this region.

The results of these AP fusion-binding studies are consistent with the genes al ready identified, ephrin-A-L1, ephrin-B2, and EphA4 being the only members of the Eph family that are expressed in the devel oping somites, but does not rule out the possible existence of other members with very similar expression profiles.

Interference of Eph family signaling affects somite formation and differentiation

To study the roles of EphA4, ephrin-A-L1, and ephrin-B2 in somitogenesis, truncated and wild-type forms of these genes and of EphB-rtk8 were overexpressed by injecting capped RNA into one cell of 1- to 4-cell stage zebrafish embryos. Truncated EphA 4 (EphA4DN), which lacks the intracellular tyrosine kinase domain, has been used previously to study the role of EphA 4 in forebrain and hindbrain development (Xu et al. 1995, 1996). Truncated EphB-rtk8 (EphB-rtk8DN) was constructed in a similar manner. Soluble forms of ephrin-A-L1 (ephrin-A-L1-Tru) and ephrin-B2 (ephrin-B2-Tru) were also constructed. Another truncated form of ephrin-B2 was also constructed (ephrin-B2-Ic), which has a transmembrane domain but lacks the intracel lular domain. This construct should bring about clustering and activation of receptors on binding, but should be incapable of transducing a ligand-dependent signal into the cell expressing the ligand construct.

Overexpression of these constructs predicted to interfere with Eph signaling disrupted somite formation, as did injection of full-length ephrin-B2 (ephrin-B2-WT) (Fig. 4). Control injections of ephrin-B2 or ephrin-A-L1 constructs that lacked the secretion signal sequence or $\beta$-galactosidase did not cause any disturbance of somitogenesis. With the injection of any particular species a variety of phenotypes were seen, ranging from the most severe in which somites failed to form, to weaker ones where segmentation produced abnormal shaped somites that were not symmetrical across the mi dline (Fig. 4A,B). In these weaker cases small extra somites were sometimes seen (Fig. 4D). The number of embryos showing a somite defect, and the severity of this phenotype, depended on the amount of RNA injected. Typically, amounts of RN A were injected that gave $40 \%$ embryos showing a weaker phenotype and $7 \%$ showing a more severe phenotype for the truncated receptors and soluble ligands; and $60 \%$ embryos showing weaker defects and $12 \%$ showing more severe ones for ephrin-B2-WT. These variations correspond to the differences in the amount of protein made in vivo from the different constructs (discussed later). It was impossible to distinguish between the phenotypes seen on the injection of the different constructs. It is unclear why both loss of border formation and ectopic boundaries (extra somites) were seen in all cases, as not enough is known of the molecular details and intracellular signaling pathways of Eph receptors and ligands.

Examination of the presomitic mesoderm and somites at the cellular level in injected embryos using the actin stain phalloidin reveals the incorrectly formed somites produced in injected embryos showing a weaker phenotype (Fig. 4D). In normal somites boundaries are symmetrical across the midline and characterized by the presence of columnar epithelial cells on either side of the furrow, whereas cells within the body of the somite are mesenchymal in appearance (Fig. 4C). Five or six-cell diameters make up the width of the somite along the anteroposterior axis. After the injection of dominant negative constructs of Eph receptors or of soluble ligands the morphology of the somite was disrupted. Where somites formed but were shaped abnormally, the cells at the boundaries showed epithelial morphology. In some cases small groups of cells were seen with the cellular morphology of somites but isolated from the midline by the existence of boundary cells on all sides (Fig. 4D). In experimental embryos defects in intersomitic furrow formation could be seen morphologically at all stages of somitogenesis, and persisted later in development (up to $28 \mathrm{hr}$ postfertilization). The defects in somite morphology did not derive from an increase in cell death as de- 

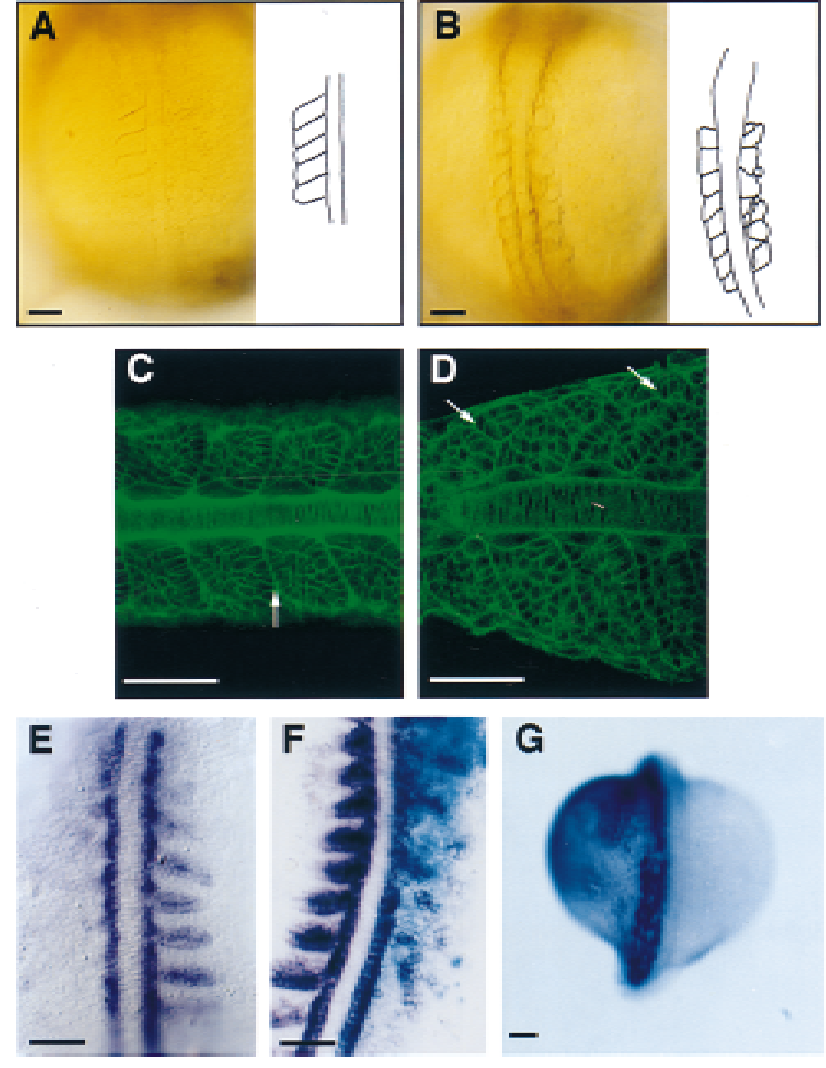

Figure4. Effect of disruption of Eph family signaling on somite formation and differentiation. Embryos were assessed at stages between 4 and 14 somites. Dorsal views, anterior is to the top (except in C and D where anterior is to the left). (A,B) Live embryos injected with ephrin-B2-WT. A camera lucida drawing adjacent to each photo shows the somite boundaries. Somites fail to form (A) or are abnormally shaped and not paired across the midline (B) in affected embryos. (C,D) Confocal microscope images of the somites of phalloidin-stained embryos. (C) A wildtype embryo. The intersomitic furrows (white arrow) and columnar-shaped epithelial cells on either side can be seen. (D) An experimental embryo injected with ephrin-B2-WT. Incorrectly positioned boundaries can be seen in the injected embryos (white arrows), these have columnar-shaped epithelial cells on either side. $(E, F)$ Experimental embryos hybridized to a myoD RNA probe (purple). (E) An embryo injected with ephrin-B2WT; (F) an embryo injected with ephrin-A-L1-Tru. Segmental myoD expression is either lost $(E)$ or disrupted $(F)$ on the injected side. The blue col or in $\mathrm{F}$ is reacted $\beta$-gal actosi dase derived from coinjected RN A. (G) An embryo injected with ephrin-B2WT reacted with EphB-rtk8-AP to show the presence and localization of ectopic protein. Ectopic ephrin-B2 is found in regions of the somites that are disrupted. Bars, $100 \mu \mathrm{m}$.

termined by $\mathrm{N}$ omarski optics, where dying cells have an increased refractive index, (Fig. 4A,B), and TUN EL labeling (data not shown).

Differentiation of somitic cell types as well as boundary formation was affected by disruption of Eph signaling. The commitment of cells to the myogenic lineage is characterized by their expression of the myogenic family of bHLH transcription factors, of which myoD is a mem- ber. The segmental expression of myoD was lost in embryos showing the most severe somite phenotypes (Fig. $4 \mathrm{E})$, and was distributed abnormally in embryos showing a weaker phenotype (Fig. 4F). The small somite-like grouping of cells seen by phalloidin staining were also visible in the myoD expression pattern suggesting that these small groups of cells behave as somites.

Expression of myoD in the adaxial cells was not affected. Adaxial cells are specified by signals from the midline structures before somite formation (Devoto et al. 1996; Blagden et al. 1997), and they are specified normally in zebrafish somite mutants in which boundary formation and segmental myoD expression are disturbed (van Eeden et al. 1996). The Eph family does not appear to be required for adaxial cell specification.

Somite defects in the embryo correspond to the localization of protein produced from injected mRNA

Analysis of protein distribution demonstrated that somite defects were localized to sites of ectopic protein production. The use of the AP fusion proteins gave an indication of the amount and local ization of active available protein in the embryos after injection of the various constructs (Fig. 4G). A fter the injection of RN A at a concentration that results in $30 \%-40 \%$ of embryos showing a somite defect, protein was detected at a concentration of 0.5-0.75 ng bound AP/ 10 embryos for dominant negative receptors and 1.5-2 ng bound AP/10 embryos for soluble ligands. This is consistent with models of receptor occupancy, where a higher concentration of ligand is required to compete with endogenous protein. A protein level of 0.1-0.2 ng bound AP/ 10 embryos was obtained after injection of full-length receptor constructs at RN A concentrations that had no effect on somite formation. At higher concentrations of injected RN A severe defects in gastrulation were observed (data not shown). The spatial distribution of the ectopic protein was determined at $70 \%$ epiboly, two somites, and $\sim 10$ somites. Protein made from the injected RNA species was found in patches in the embryo throughout the period studied. By 10 somites the protein was found on one side of the embryo or in discrete patches. Where protein was detected in the somites, the development of the somites was abnormal (Fig. 4G). Therefore, protein made from injected RNA species was found in the embryo at the stages at which the phenotype described is seen, and in a distribution that corresponds to the site of the defects.

\section{Somite defects can be rescued by coinjecting with full-length receptor}

If somite defects are caused specifically by the interfering versions of Eph receptors or ephrins, then it should be possible to reduce the severity of the defects by competing with wild-type forms of the proteins. Coinjection of RNA encoding either full-length EphA4 or EphB-rtk8 with ephrin-B2-Tru reduced the percentage of defective embryos compared to injection of ephrin-B2-Tru alone (Table 1; Fig. 5A,B). Similarly, coinjection of EphA4 was 
Table 1. Rescue of somite abnormalities by the coinjection of full-length receptor with truncated ligand

\begin{tabular}{|c|c|c|c|c|c|c|c|c|c|}
\hline & \multicolumn{3}{|c|}{ Full-length receptor } & \multicolumn{3}{|c|}{ Truncated ligand } & \multicolumn{3}{|c|}{$\begin{array}{l}\text { Full-length receptor } \\
\text { plus truncated ligand }\end{array}$} \\
\hline & no. & S-ab & percent & no. & S-ab & percent & no. & S-ab & percent \\
\hline EphA4 + ephrin-B2-Tru & 84 & 6 & 7 & 90 & 28 & 31 & 111 & 10 & 9 \\
\hline EphB-rtk8 + ephrin-B2-Tru & 121 & 7 & 6 & 81 & 23 & 28 & 123 & 14 & 11 \\
\hline EphA4 + ephrin-A-L1 & 138 & 11 & 8 & 128 & 44 & 34 & 134 & 16 & 12 \\
\hline EphB-rtk8 + ephrin-A-L1 & 64 & 5 & 8 & 70 & 18 & 26 & 103 & 27 & 26 \\
\hline
\end{tabular}

In all cases, RN A encoding $\beta$-galactosidase was co-injected. Full-length receptors do not give a somite phenotype (S-ab), whereas the truncated ligands ephrin-B2 and ephrin-A-L1 do. When mixed together and injected the RN As show different patterns of rescue. The phenotype generated by the truncated form of ephrin-B2 is rescued by both EphA 4 and EphB-rtk8, which is consistent with this ligand being able to bind to both of these receptors. In contrast, the phenotype produced by the truncated ephrin-A-L1 is rescued by EphA 4 but not by EphB-rtk8, again matching the predictions of the AP fusion ligand and receptor binding studies. (no.) N umber of embryos injected; (percent) percentage of injected embryos showing a somite abnormality.

able to rescue the defects caused by injection of ephrinA-L1-Tru (Table 1). At concentrations effective in rescuing ephrin-B2-Tru-induced defects, EphB-rtk8 was unable to rescue defects caused by ephrin-A-L1-Tru (Table 1; Fig. 5C,D). These results are consistent with the re-
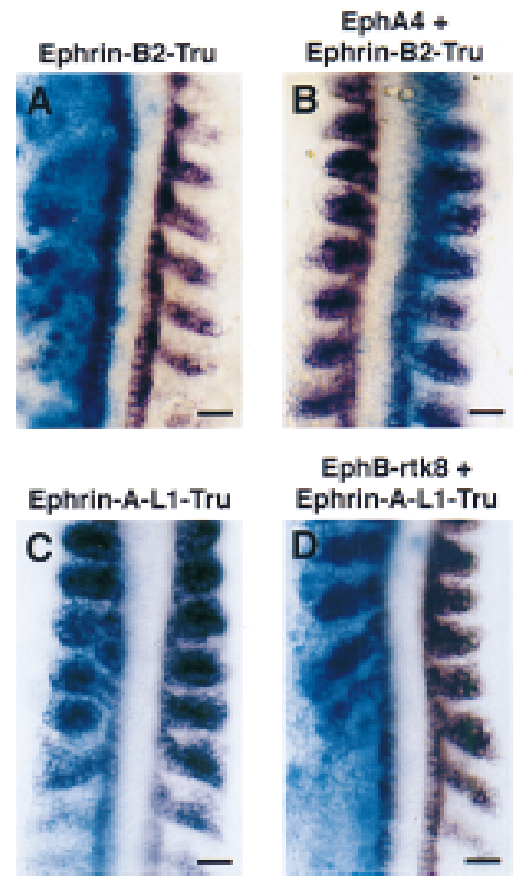

Figure 5. Visualization of the rescue experiments using myoD expression. Embryos were hybridized with a digoxigenin-label ed antisense RN A myoD probe. Embryos are between 10 and 14 somites. Dorsal views, anterior is to the top. Blue staining marks the local ization of coinjected $\beta$-gal actosi dase RN A. Embryos shown were injected with (A) ephrin-B2-Tru, (B) EphA4 and ephrin-B2-Tru, (C) ephrin-A-L1-Tru, and (D) EphB-rtk8 and ephrin-A-L1-Tru. Disrupted segmental myoD expression is seen on the injection of truncated forms of ephrin-B2 (A) and ephrin-A-L1 (C). Coinjection of EphA4 with ephrin-B2-Tru rescues the myoD expression (B); whereas coinjection of EphB-rtk8 has no effect on the ephrin-A-L1-Tru phenotype (D). Bars, 50 $\mu \mathrm{m}$. ceptor-binding profiles determined in vitro and indicate that the somite phenotypes seen in embryos injected with ephrin-A-L1-Tru and ephrin-B2-Tru are attributable to disruption of endogenous Eph family signaling. To ensure that when two species of RN A were injected both were translated we determined the protein levels of ephrin-A-L1-tru and EphB-rtk8 in embryos that had been injected with RNA encoding these two proteins in isolation or when coinjected. The protein levels determined were 0.28 and $0.30 \mathrm{ng}$ bound $\mathrm{AP} / 10$ embryos for ephrin-A-L1-Tru and 0.50 and $0.63 \mathrm{ng}$ bound AP/10 embryos for EphB-rtk8 in isolation and when coinjected, respectively. This suggests that rescue by coinjection of two different RN A species, at these concentrations, does not result from an overloading of the translation machinery and a reduction in the level of active protein. Therefore, the observed defects in somitogenesis are a specific result of interfering with Eph family signaling.

Eph family signaling is required for the regulation of her1, Delta D, and paraxis expression in the presomitic mesoderm

To determine whether the somite defects derived from the effects of exogenous Eph proteins during gastrulation, in situ hybridizations with probes to no tail (ntl), snail1 (sna1), and her1 were carried out on injected embryos between the stages of $60 \%$ and $90 \%$ epiboly. $\mathrm{Ntl}$ and snal are expressed in the germ ring and involuting mesoderm during gastrulation (Schulte-Merker et al. 1994; Thisse et al. 1994) and, therefore, are good indicators of the normal progress of gastrulation. The expression patterns of these two genes and of herl were normal during these stages (data not shown), indicating that gastrul ation was not disrupted in injected embryos and that mesoderm migration was unaffected.

During the late stages of gastrulation, $75 \%-100 \%$ epiboly, herl is restricted to a segmental prepattern. This was al so seen in injected embryos showing that the segmental prepattern is laid down correctly in injected embryos. However, from bud stage herl expression was disturbed in injected embryos, the anterior stripe of ex- 
pression was regulated consistently abnormally in experimental embryos (Fig. 6B,C).

The expressi on patterns of genes known to be involved in somite formation, her 1 , Delta $D$, and paraxis (par1), and patterning, FGF-8, were examined in injected embryos at the 8- to 12-somite stage when defects in boundary formation were clearly visible. The analysis of all markers was carried out for embryos in which the ephrins ephrin-B2-WT, ephrin-B2-Tru, ephrin-B2-IC, or ephrin-A-L1-Tru and the receptors EphB-rtk8DN or EphA4DN had been overexpressed. The results were essentially the same for each of these cases and representative

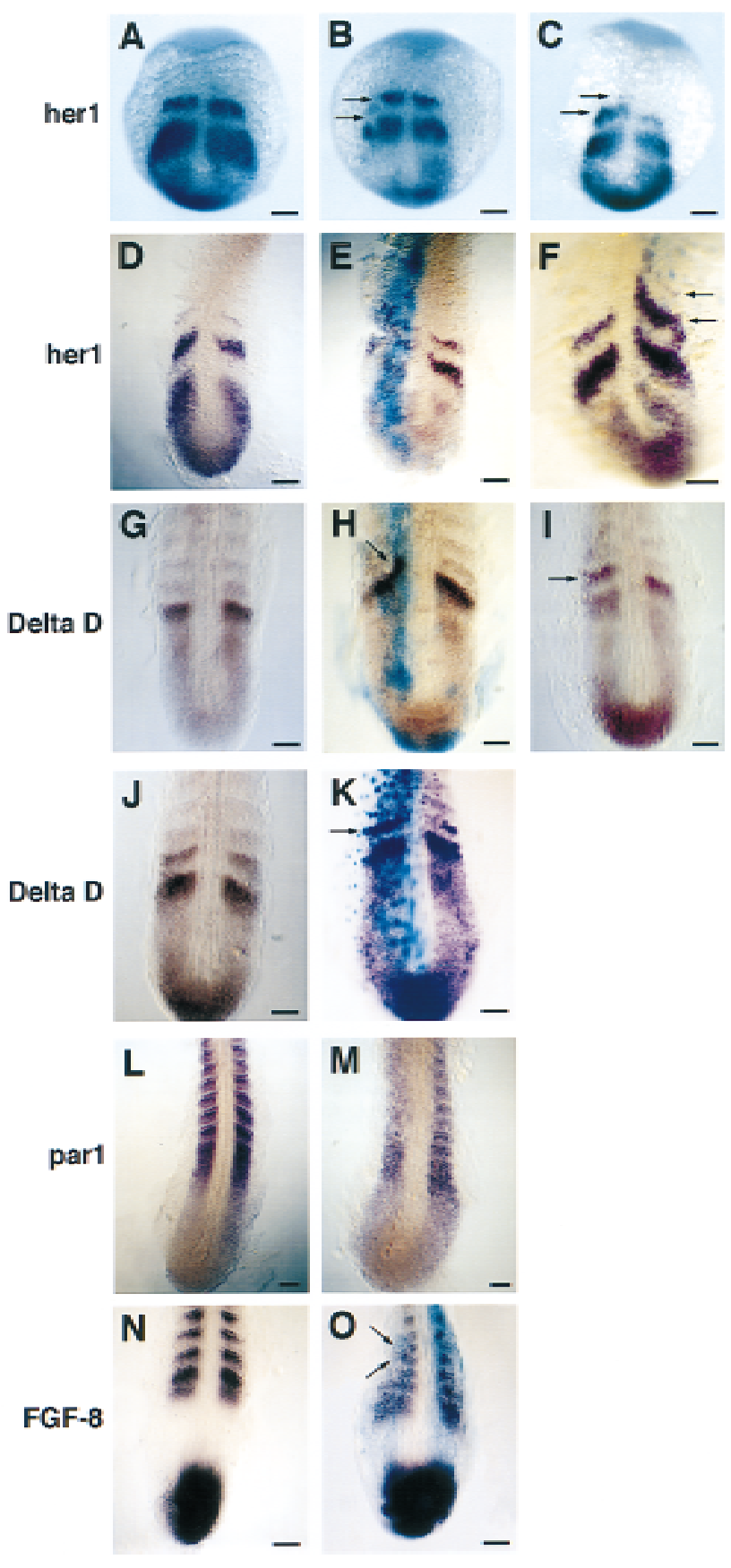

embryos are shown in Figure 6. The severity and number of embryos affected varied between different injection experiments depending on the amount of RN A injected and ectopic protein produced in vivo. The disruptions seen in the expression of the marker genes reflected the number and degree of morphological defects observed within each experimental batch of embryos.

At the 8- to 12-somite stage in control embryos her1 is expressed in two or three stripes in the presomitic mesoderm that correspond to the primordia of alternating odd numbered somites (Fig. 6D; Muller et al. 1996). The effects of RNA injections on herl expression varied; in
Figure 6. Effect of the disruption of Eph family signaling on the segmental pattern in the presomitic mesoderm and on patterning of the somites. Dorsal views, anterior is to the top. Blue staining $(\mathrm{E}, \mathrm{F}, \mathrm{H}, \mathrm{K}, \mathrm{O})$ marks local ization of coinjected $\beta$-gal actosi dase RN A. (A) Wild-type her1 expression in a two-somite embryo. $(B, C)$ herl expression in two-somite embryos injected with ephrin-B2-WT. The anterior stripes of herl expression are either disrupted (arrows in $B$ ), or expression is maintained anteriorly such that extra stripes are seen (arrows in C), on the injected side. (D) Wild-type expression of herl in a 12-somite embryo. $(E, F)$ herl expression in 12somite embryos injected with ephrin-B2-WT and EphB-rtk8DN, respectively. Once again the anterior stripes of her 1 expression are either disturbed (injected side in E), or expression is not switched off correctly, resulting in the presence of an extra stripe anteriorly (arrows in F). $(G, J)$ The dynamic nature of Delta D expression in 12-somite control embryos, either one $(\mathrm{G})$ or two $(\mathrm{J})$ stripes are seen in the anterior presomitic mesoderm. $(\mathrm{H}, \mathrm{I}, \mathrm{K})$ Delta $\mathrm{D}$ expression in embryos injected with ephrin-B2-WT, ephrin-B2-Ic, and EphBrtk8DN, respectively. Delta $D$ expression is incorrectly regulated in injected embryos, resulting in disrupted stripes of expression (arrow in $\mathrm{H}$ ), or persistence of expression such that extra stripes are seen anteriorly on the injected side (arrows in I and K). (L)Wild-type expression of par1 in a 12-somite embryo. (M) parl expression in a 12-somite embryo injected with ephrin-B2-WT. Par1 is not restricted to its usual segmental pattern on the injected side where somites have failed to form. (N) Wild-type FGF-8 expression in a 12-somite embryo. (O) FGF-8 expression in a 12-somite embryo injected with ephrin-B2-Ic. FGF-8 is expressed in an anterior domain of abnormally shaped somites in the injected embryo (arrows in O). (A-C) Bar, $50 \mu \mathrm{m}$; (D-O) bar, $100 \mu \mathrm{m}$. 
some cases irregularly shaped stripes or small patches of her1 expression were found (Fig. 6E), and in others the expression was disrupted and shifted anteriorly by the distance of approximately one band of herl expression (Fig. 6F). However, expression of herl was maintained caudally in the tail bud. Somites failed to form in embryos with an extra band of herl expression.

In control 8- to 12-somite embryos zebrafish Delta D is expressed at high levels in one or two stripes in the anterior presomitic mesoderm, at a lower level in the anterior of each of the formed somites and in the extending tailbud (Fig. 6G,J; Dornseifer et al. 1997). In experimental embryos expression of Delta D was disrupted and shifted anteriorly in regions where somite formation had been disturbed but was not affected in the tailbud (Fig. $6 \mathrm{H}, \mathrm{I}, \mathrm{K})$. In embryos that failed to segment an extra stripe of Delta $D$ expression was seen anterior to its normal expression domain on the injected side (Fig. 6I,K).

A zebrafish paraxis gene, par1, has been cloned recently (Shanmugalingam and Wilson 1998). In control embryos par1 expression is detected uniformly throughout the presomitic mesoderm but after somite formation it is stronger in an anterior domain of each somite (Fig. $6 \mathrm{~L})$. This expression pattern is similar to that described for the mouse homolog (Burgess et al. 1995). Injected embryos showing a somite phenotype also had a disrupted parl expression pattern; in regi ons where somites failed to form par1 expression was not restricted to its usual segmental pattern, but remained expressed uniformly, as in the presomitic mesoderm (Fig. 6M).

These results suggest that Eph signaling is not required for the establishment of the segmental prepattern in the paraxial mesoderm. However, disruption of Eph signaling does affect the regulation and switching off of both her1 and Delta D in the anterior presomitic mesoderm, as well as the regulation of parl gene expression.

As an indication of anteroposterior patterning within the disrupted somites in situ hybridization with probes for FGF-8 or myoD as performed. At the 10-somite stage FGF-8 is expressed throughout the anterior presomitic mesoderm and becomes restricted to an anterior domain of cells in the formed somites (Fig. 6N). In injected embryos FGF-8 expression was restricted to an anterior domain even within the abnormally shaped somites (Fig. 60 ). Also in the affected somites myoD expression was detected in a posterior domain as is the case in normally formed somites at these stages (see Fig. 4F). These results indicate that the anteroposterior patterning within the somites is not affected by disruption of Eph signaling.

Relationship between EphA4, ephrin-B2, and herl expression

Because the timing of the defects in herl expression corresponded to the onset of segmental expression of EphA4 and ephrin-B2 in the presomitic mesoderm, we investigated in more detail, the relationship between herl expression and these genes. Double in situ hybridizations with probes for EphA4 plus ephrin-B2, her1 plus EphA4, and her1 plus ephrin-B2 were undertaken in control embryos (Fig. 7).

ephrin-B2 and EphA4 are expressed in alternating stripes in the somites and presomitic mesoderm with EphA 4 being in the anterior cells of each somite and ephrin-B2 in the posterior cells (Fig. 7A). There is an interface between these expression domains within each somite and within the most anterior presumptive
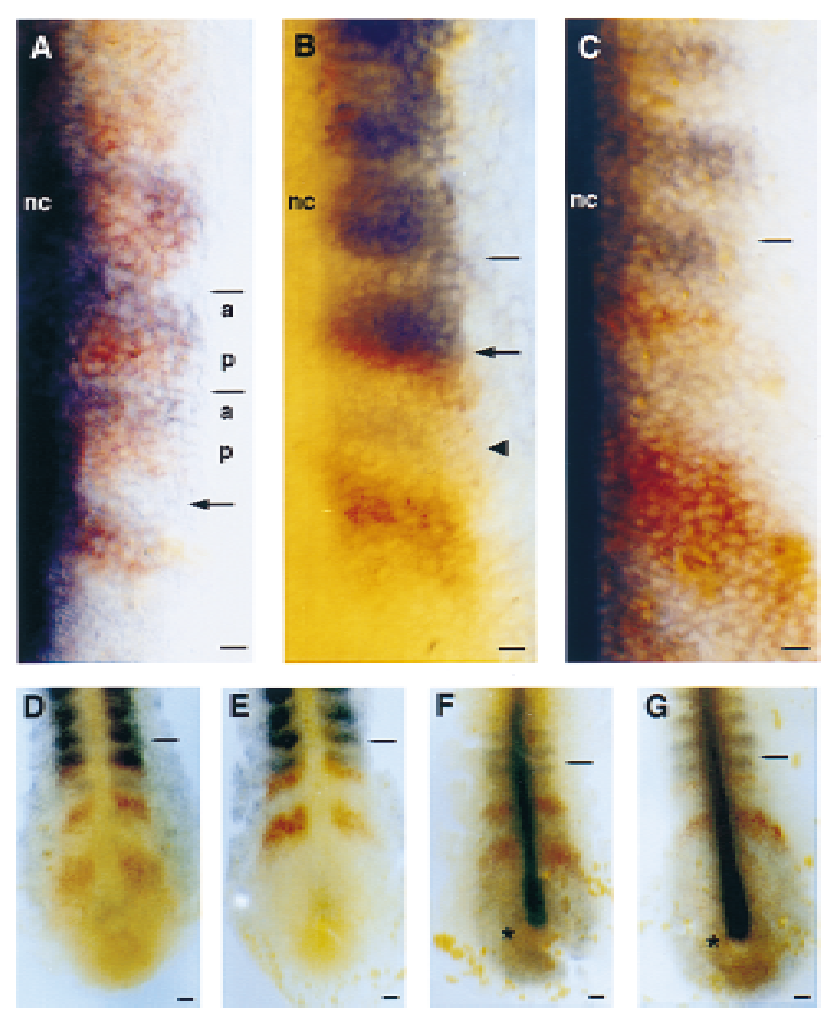

Figure 7. Relationship of ephrin-B2, EphA4, and her-1 expression in the anterior presomitic mesoderm and posterior somites. Embryos were hybridized with digoxigenin- and fluorescein-labeled antisense RNA probes. Dorsal views, anterior is to the top, of six-somite $(A, B, C, D, E, G)$ and five-somite $(F)$ stage embryos. (A) EphA4 (blue) is expressed in an anterior domain of the formed somites and most anterior presumptive somites, whereas ephrin-B2 (red) is expressed in a posterior domain of these segments (lines mark the two most posterior somite boundaries). In the anterior presomitic mesoderm a row of nonexpressing cells is found at the position where the next somite boundary will form (arrow). (B,D,E) ephrin-B2 (blue) and her-1 (red) expression. Herl expression is lost in an anterior to posterior direction in the most anterior presumptive somite (line marks the last formed somite boundary), which corresponds with the posterior expansion of the ephrin-B2 expression domain in the same region, such that cells expressing both genes are seen (arrow in B). Expression of ephrin-B2 is seen between the two most anterior stripes of herl expression (arrowhead in B). (C,F,G) EphA4 (blue) and her-1 (red) expression. EphA4 and herl expression are not seen juxtaposed in the anterior presomitic mesoderm (line marks the last formed somite boundary). Low level expression of EphA4 is al so seen throughout the paraxial mesoderm (stars in $\mathrm{F}$ and $\mathrm{G}$ ). (a) Anterior; (nc) notochord; (p) posterior; bars, $50 \mu \mathrm{m}$. 
somites. EphA4 and ephrin-B2 expression domains al so meet where boundaries have formed. However, within the presomitic mesoderm, at the position where the next somite boundary is to form, there is a single row of nonexpressing cells between the ephrin-B2 and EphA4 expression domains. ephrin-B2 expression expands caudally such that once a somite has formed there is no Ionger a gap between the expression of these two genes.

Her 1 is expressed in bands of cells of one somite width in the presomitic mesoderm alternating with regions of similar width devoid of herl expression. These bands of expression correspond to somitic primordia (Muller et al. 1996). As the presumptive somite develops, herl expression is lost in an anterior to posterior di rection (M uller et al. 1996; Fig. 7). The expression and subsequent caudal expansion of ephrin-B2 within the presomitic mesoderm corresponds to the timing of the reduction in herl expression within its most anterior domain and cells coexpressing both genes are seen (Fig. 7B,D,E). EphA4 is expressed in the anterior of the formed and the most anterior-forming somites. The distance between the EphA4 and herl expression domains varied significantly as a result of herl being expressed only in alternate somite primordia (Fig. 7C,F,G).

\section{Discussion}

The results presented here demonstrate a role for Eph signaling in the formation and differentiation of somites. We demonstrate the iterative expression of members of this family within the presomitic and somitic mesoderm and illustrate that interfering with Eph si gnaling leads to loss or incorrect formation of somite boundaries and disruption of myogenic differentiation. The defects in boundary formation are reminiscent of those reported on disturbance of Notch/Delta signaling (Conlon et al. 1995; Dornseifer et al. 1997; Jen et al. 1997) and disruption of Eph signaling prevents the correct regulation of Delta $D$ expression in the developing somites. These results suggest that $\mathrm{N}$ otch/Delta signal ing and Eph signaling may function together to establish somite boundaries. We have investigated the mechanism underlying the somite defect with regard to the segmental pattern as illustrated by herl expression. The results show that the establishment of this segmental pattern is unaffected by disruption of Eph signaling, rather it is the translation of the prepattern into somites that is disturbed.

Eph signaling affects the translation of the segmental prepattern into somites

Evidence for the existence of a segmental pattern within the presomitic mesoderm came from embryological experiments including transplantation of presomitic tissue in chicks and heat shock of Xenopus embryos (Keynes and Stern 1988; Gossler and Hrabe de Angelis 1998). These results suggest that the process of segmentation is organized in the presomitic mesoderm before the somite boundaries are formed. Recently molecular evidence for the existence of this presomitic segmental pattern has been obtained. Homologs of the Drosophila pair-rule gene hairy, which is involved in embryonic segmentation, have been cloned in zebrafish, herl, and chick, chairy-1. herl is expressed in stripes in the presomitic mesoderm that correspond to al ternate somite primordia (Muller et al. 1996), whereas c-hairy-1 has a dynamic expression pattern that passes through a characteristic cycle during the formation of each somite (Palmeirim et al. 1997). How the segmental pattern is established in the presomitic mesoderm remains unclear, although the c-hairy-1 expression pattern provides molecular evidence for the existence of a developmental clock linked to segmentation (Cooke 1998). This is consistent with the Clock and Wavefront model (Cooke and Zeeman 1976), which proposes that a segmental pattern is established through the interaction of two components that are temporally and spatially regulated. The disruption of Eph family signaling does not affect the establishment of the prepattern, indicating that Eph function is not required for this process. However, the later regulation of herl expression is disrupted and subsequently, somites fail to form or form aberrantly. This suggests that Eph family signaling is required to translate the prepattern into the events of somite boundary formation and differentiation (Fig. 8). These processes appear to require the switching off of transcriptional repressors such as herl, and the refinement of expression patterns of signaling molecules such as Delta D.

\section{Anteroposterior polarity exists within the presumptive somites}

The expression patterns of ephrin-B2 and EphA4 within the anterior presomitic mesoderm indicate that the presumptive somites are patterned along the anteroposterior axis before boundary formation, as ephrin-B2 is expressed within a posterior domain and EphA4 an anterior domain of the most rostral somite primordia. In addition, the signaling proteins Delta D and FGF-8 also become restricted to the anterior domain of the somite as segmentation occurs (Dornsei fer et al . 1997; Furthauer et al. 1997; Fig. 6J,N ). In contrast, myoD is expressed in the posterior part of the somite from the 10-somite stage (Wei nberg et al. 1996). These anteroposterior restrictions of Eph, FGF, and Delta signaling proteins before, or as segmention occurs, suggest that anteroposterior patterning of each segment is occurring in the presomitic mesoderm. The existence of an anteroposterior pattern within presumptive somites was al so suggested by grafting experiments in chicks, in which a boundary was only seen to form when anterior and posterior somite cells were juxtaposed (Stern and Keynes 1987).

\section{Expression of EphA4 and ephrin-B2 suggest a role in boundary formation}

In Xenopus, chick, rat, and mouse a number of members of the Eph family are expressed in the somites, including EphA3, EphB3, ephrin-B1, and ephrin-A5 (Fletcher et al. 
Figure 8. Diagrammatic representation of the relationship between her1, EphA4, and ephrin-B2 in a single file of cells along the anteroposterior axis of the paraxial mesoderm during somitogenesis. The three columns represent the cells over a period of time during which two somites are added. herl expression is shown in hatched circles, EphA4 expression in light shading, and ephrin-B2 expression in dark shading. Where herl and EphA4 expression overlap lightly shaded hatched circles are used, and where herl and ephrin-B2 expression overlap darkly shaded hatched circles are used.

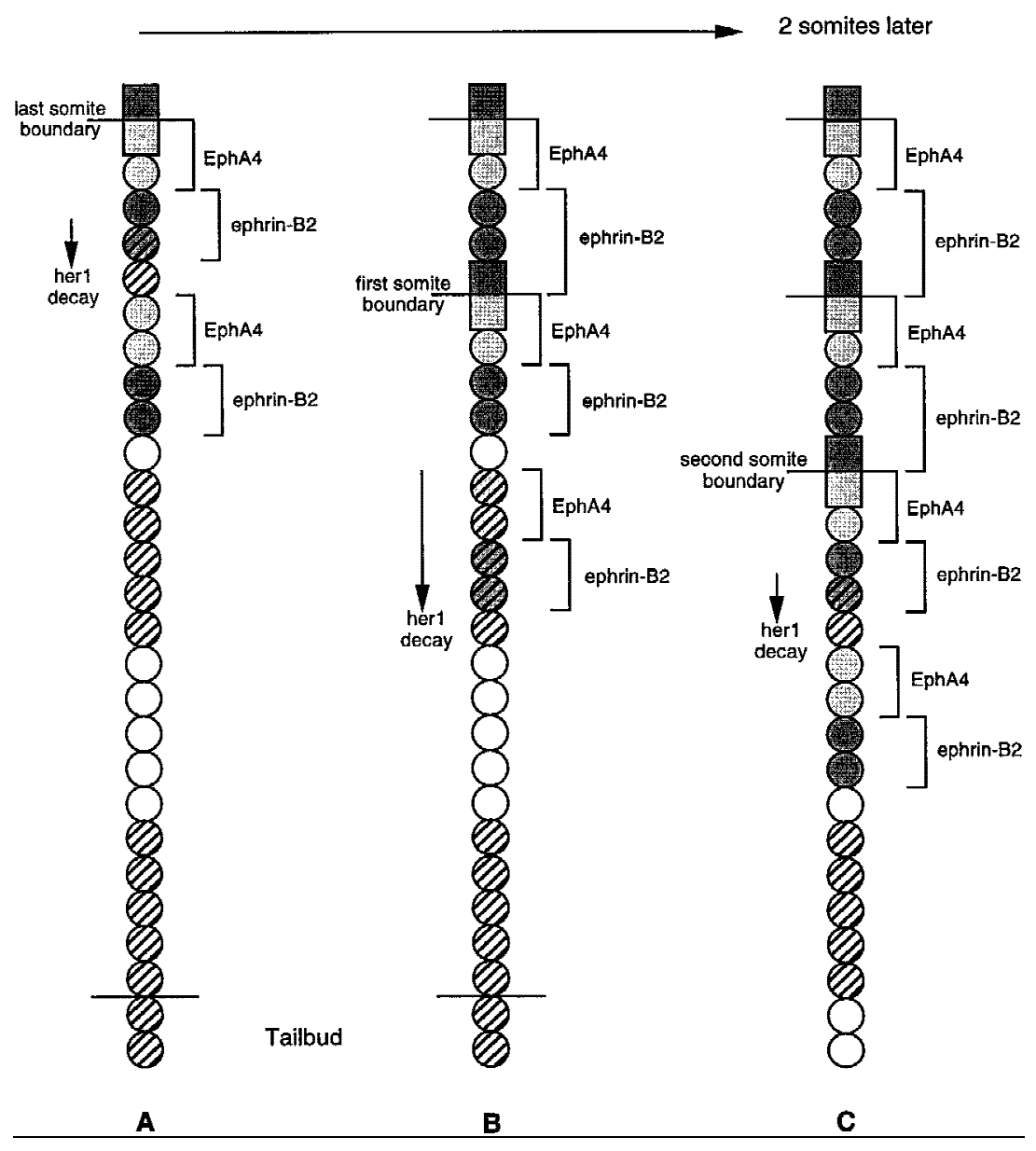

1994; Kilpatrick et al. 1996). Only EphA4 and ephrin-B2 have been shown previously to be expressed segmentally in the presomitic mesoderm in mouse and chick (Bergemann et al. 1995; Irving et al. 1996). In zebrafish EphA4 and ephrin-B2 are expressed sequentially along the anteroposterior axis of the embryo within the somitic and anterior presomitic mesoderm. The similarity of the expression patterns of these two genes in zebrafish and higher vertebrates suggest that their function within the presomitic mesoderm may be conserved. In zebrafish somites form by a process of local deadhesion within the presomitic mesoderm (Wood and Thorogood 1994). As the Eph family of proteins have been shown to mediate an inhibition of cell movement and growth cone collapse (Drescher et al. 1995; Brennan et al. 1997; Wang and Anderson 1997), and the temporal and spatial expression patterns of EphA4 and ephrin-B2 correlate with boundary formation, these are suitabl e molecules to play a role in this process of deadhesion. These proteins al so play a role in segmentation in the hindbrain (Xu et al. 1995).

In zebrafish, as a somite boundary forms the cells on either side of the border undergo a shape change from mesenchymal to epithelial (Fig. 4C,D). A s class B ephrins have been shown to be capable of intracellular signaling, the presence of ephrin-B2 in cells on one side of the boundary and EphA4 in cells on the other suggests that bidirectional signaling by way of these molecules could be involved in the cell shape changes required for furrow formation. The Eph family of receptors have been shown to associate with the GTPase rasGAP (Holland et al. 1997) and the SH2 domain containing adapter protein Nck (Stein et al. 1998), both of which are able to influence cytoskeletal architecture (McGlade et al. 1993). Also, al terations of both the actin cytoskeleton and microtubules have been visualized in axon growth cones after their exposure to $A$ and $B$ class ephrins (M eima et al. 1997a,b). These observations show that Eph receptors are capable of affecting the cytoskeleton, and therefore could mediate the cell shape changes required for somite boundary formation. Juxtaposition of EphA4 and ephrinB2-expressing cells is not the only requirement for boundary formation, as these are al so expressed in adjacent cells in the center of each somite where no boundary forms. This suggests that Eph signaling acts coordinatel y with other processes to bring about somite boundary formation.

\section{Materials and methods}

Maintenance of fish

Breeding fish were maintained at $28.5^{\circ} \mathrm{C}$ on a $14-\mathrm{hr}$ light/ $10-\mathrm{hr}$ 
dark cycle. Embryos were collected by natural spawning and staged according to Kimmel et al. (1995).

\section{CDNA cloning and sequencing}

Ephrin-A-L1 was cloned as previously described (Brennan et al. 1997). For the cloning of ephrin-B2 degenerate primers were designed to conserved regions (FTIKFQE and YYIVQEM) and were used for amplification of a zebrafish neurula stage library. The PCR product was used as a probe to screen the neurula stage CDNA library at low stringency. Individual clones containing the entire open reading frame of ephrin-B2 were isolated (GenBank accession no. AJ004863).

Partial CDN A clones encoding the 5 ' region of the Eph class B receptor EphB-rtk8 coding sequence were isolated after high stringency screening of a random primed 3- to 15-hr zebrafish cDN A library. A $0.2-k b$ fragment of a previously isolated partial cDN A of EphB-rtk8 (Cooke et al. 1997) was used as the probe. The entire open reading frame of EphB-rtk8 was then contained within two overlapping cDNA clones (GenBank accession no. AJ005029).

\section{Cytoskeleton staining}

Phalloidin staining was performed as described previously (Whitfield et al. 1996).

\section{Detection of cell death}

Cell death was detected by the method of terminal transferase dUTP nick end labeling (TUNEL, ApopTag In situ Apoptosis Detection Kit, Peroxidase; Oncor Inc.) (A bdelilah et al. 1996).

\section{Whole mount in situ hybridization and immunostaining}

Whole mount in situ hybridization using digoxigenin-labeled anti-sense RNA probes was performed as described (Xu et al. 1994).

Whole mount and cell alkaline phosphatase binding studies

Whole mount alkaline phosphatase-binding studies were performed as described previously (Cheng and Flanagan 1994; Brennan et al. 1997).

Quantitative assay for APtag-Eph protein binding to embryos

To quantitate the amount of ectopic protein made after the injection of RNA encoding Eph family proteins we determined the amount of AP fusion protein bound to the embryos using the colorimetric method of Berger et al. (1988; Flanagan and Leder 1990).

Preparation of synthetic RNA and microinjection of zebrafish embryos

Capped RN A was synthesized by in vitro transcription of linearized plasmids and RN A concentration was determined spectrophotometrically. RNA was injected in a volume of $\sim 200 \mathrm{pl}$ into one cell of a one- to four-cell stage zebrafish embryo, using a glass capillary needle attached to a Picospritzer. The amount of RNA injected was, for the ligand constructs $60-100 \mathrm{ng} / \mu \mathrm{l}$, and for the dominant negative receptor constructs $300-400 \mathrm{ng} /$ $\mu \mathrm{l}$ and $150-200 \mathrm{ng} / \mu \mathrm{l}$ for the full-length receptor constructs.

To control for nonspecific effects of RNA injection, ephrinA-L1 and ephrin-B2 constructs that lack signal sequences were injected. The distribution of injected RNA in vivo was determined by coinjecting with RNA encoding $\beta$-galactosidase. The two species of RNA broadly segregate together during development (Griffin et al. 1995), and the distribution of $\beta$-gal actosi dase can be determined subsequently by staining for enzyme activity.

\section{Acknowledgments}

We thank our colleagues in the Holder and Wilson laboratories for their comments and criticisms during the course of this work. We thank Leila Abbas and Juliet Williams for help with phalloidin and TUNEL staining, respectively. We also thank Jose Campos-Ortega, Eric Weinberg, David Wilkinson, John Flanagan, Julian Lewis, and Didier Stainier for providing us with probes. Thanks also to Steve Wilson, Simon Hughes, Rudiger Klein, Andrew Boyd, and M artin Lackmann for discussions and for sharing their results before publication. The work was supported financially by the Well come Trust, a Biotechnology and Biological Sciences Council Research (BBSRC) program grant, the Medical Research Council, and the Human Frontier Science Program. K.S. is a recipient of a Japanese Society for the Promotion of Science postdoctoral fellowship for research abroad.

The publication costs of this article were defrayed in part by payment of page charges. This article must therefore be hereby marked 'advertisement' in accordance with 18 USC section 1734 solely to indicate this fact.

\section{References}

Abdelilah, S., E. Mountcastle-Shah, M. Harvey, L. SolnicaKrezel, A. Schier, D. Stemple, J. Malicki, S. Neuhauss, F. Zwartkruis, D. Stainier, Z. Rangini, and W. Driever. 1996. Mutations affecting neural survival in the zebrafish Danio rerio. Development 123: 217-227.

Bartley, T. D., R.W. Hunt, A.A. Welcher, W.J. Boyle, V.P. Parker, R.A. Lindberg, H.S. Lu, A.M. Colombero, R.A. Elliot, B.A. Guthrie, P.L. Holst, J.D. Skrine, R.J. Toso, M. Zhang, E. Fernandez, G. Trail, T. Hunter, and G.M. Fox. 1994. B61 is a ligand for the ECK receptor protein-tyrosine kinase. Nature 368: 558-560.

Bergemann, A., C. Hwai-Jong, R. Brambilla, R. Klein, and J. Flanagan. 1995. Elf-2, a new member of the Eph ligand family, is segmentally expressed in mouse embryos in the region of the hindbrain and newly forming somites. Mol. Cell. Biol. 15: 4921-4929.

Berger, J., J. Hauber, R. Hauber, R. Geiger, and B. Cullen. 1988. Secreted placental alkaline phosphatases: A powerful new quantitative indicator of gene expression in eukaryotic cells. Gene 66: 1-10.

Blagden, C., P. Currie, P. Ingham, and S. Hughes. 1997. N otochord induction of zebrafish slow muscle is mediated by sonic hedgehog. Genes \& Dev. 11: 2163-2175.

Brambilla, R., A. Schnapp, F. Casagranda, J. Labrador, A. Bergeman, J. Flanagan, E. Pasquale, and R. Klein. 1995. Membrane bound LERK2 ligand can signal through three different Ephrelated receptor tryrosine kinases. EMBO J. 14: 3116-3126.

Brennan, C., B. M onshau, R. Lindberg, B. Guthrie, U. Drescher, F. Bonhoeffer, and N. Holder. 1997. Two Eph receptor tyrosine kinase ligands control axon growth and may be involved in the creation of the retinotectal map in zebrafish. Development 124: 655-664.

Bruckner, K., E. Pasquale, and R. Klein. 1997. Tyrosine phosphorylation of transmembrane ligands for Eph receptors. Sci- 
ence 275: 1640-1643.

Burgess, R., P. Cserjesi, K. Ligon, and E. Olson. 1995. Paraxis: A basic helix-loop-helix protein expressed in paraxial mesoderm and developing somites. Dev. Biol. 168: 296-306.

Cheng, H.-J. and J. Flanagan. 1994. Identification and cloning of ELF-1, a devel opmentally expressed ligand for the M ek 4 and Sek 1 receptor tyrosine kinases. Cell 79: 157-168.

Conlon, R., A. Reaune, and J. Rossant. 1995. N otch1 is required for the coordinate segmentation of somites. Development 121: 1533-1545.

Cooke, J. 1998. A gene that resusitates a theory-Somitogenesis and a molecular oscillator. Trends Genet. 14: 85-88.

Cooke, J. and E. Zeeman. 1976. A clock and wavefront model for control of the numbers of repeated structures during animal morphogenesis. J. Theoret. Biol. 58: 455-476.

Cooke, J., Q. Xu, S. Wilson, and N. Holder. 1997. Characterisation of five novel zebrafish Eph-related receptor tyrosine kinases suggests roles in neural patterning. Genes Dev. Evol. 206: 515-531.

Devoto, S., E. Melancon, J. Eisen, and M. Westerfield. 1996. Identification of separate slow and fast muscle precursor cells in vivo, prior to somite formation. Development 122: 3371-3380.

Dornseifer, P., C. Takke, and J. Campos-Ortega. 1997. Overexpression of a zebrafish homologue of the Drosophila neurogenic gene Delta perturbs differentiation of primary neurons and somite development. Mech. Dev. 1-13.

Drescher, U., C. Kremoser, C. Handwerker, J. Loschinger, M. N oda, and F. Bonhoeffer. 1995. In vitro guidance of retinal ganglion cell axons by RAGS, a 25kDa tectal protein related to the ligands for Eph receptor tyrosine kinases. Cell 82: 359-370.

Flanagan, J. and P. Leder. 1990. The Kit ligand: A cell surface molecule altered in steel mutant fibroblasts. Cell 63: 185194.

Flenniken, A., N. Gale, G. Yancopoulos, and D. Wilkinson. 1996. Distinct and overlapping expression patterns of ligands for Eph rel ated receptor tyrosine kinases during mouse development. Dev. Biol. 179: 382-401.

Fletcher, F., M. Carpenter, H. Shilling, P. Baum, S. Ziegler, S. Gimpel, T. Hollingsworth, T. Vanden Bos, L. James, K. Hjerrild, B. Davison, S. Lyman, and M. Beckmann. 1994. LERK-2, a binding protein for the receptor-tyrosine kinase ELK, is evolutionarily conserved and expressed in a developmentally regulated pattern. Oncogene 9: 3241-3247.

Furthaver, M., C. Thisse, and B. Thisse. 1997. A role for FGF-8 in the dorsoventral patterning of the zebrafish gastrula. De velopment 124: 4253-4264.

Gale, N . and G. Yancopoulos. 1997. Ephrins and their receptors: A repulsive topic. Cell Tiss. Res. 290: 227-241.

Gale, N., S. Holland, D. Valenzuela, A. Flenniken, L. Pan, T. Ryan, M. Henkemeyer, K. Strebhardt, H. Hirai, D. Wilkinson, T. Pawson, S. Davis, and G. Yancopoulos. 1996. Eph receptors and ligands comprise two major specificity subclasses and are reciprocally compartmentalized during embryogenesis. Neuron 17: 9-19.

Gossler, A. and M. Hrabe deAngel is. 1998. Somitogenesis. Curr. Top. Dev. Biol. 38: 225-287.

Griffin, K., R. Patient, and N. Holder. 1995. Analysis of FGF function in normal and no tail zebrafish embryos reveals separate mechanisms for formation of the trunk and tail. Devel opment 121: 2983-2994.

Holland, S., N. Gale, G. Gish, R. Roth, Z. Songyang, L. Cantley, M. Henkemeyer, G. Y ancopolos, and T. Pawson. 1997. Juxtamembrane tyrosine residues couple the Eph family receptor EphB2/Nuk to specific SH2 domain proteins in neuronal cells. EMBO J. 16: 3877-3888.

Holland, S., N. Gale, G. M bamalu, G. Yancopoulos, M. Henkemeyer, and T. Pawson. 1996. Bidirectional signaling through the Eph-family receptor $\mathrm{N}$ uk and its transmembrane ligands. Nature 383: 722-725.

Irving, C., A. Nieto, R. DasGupta, P. Charnay, and D. Wilkinson. 1996. Progressive spatial restriction of Sek-1 and krox20 gene expression during hindbrain segmentation. Dev. Biol. 173: 26-38.

Jen, W., D. Wettstein, D. Turner, A. Chitnis, and C. Kintner. 1997. The N otch ligand, X-Delta-2, mediates segmentation of the paraxial mesoderm in Xenopus embryos. Development 124: 1169-1178.

Keynes, R. and C. Stern. 1988. Mechanisms of vertebrate segmentation. Development 103: 413-429.

Kimmel, C.B., W.W. Ballard, S.R. Kimmel, B. Ullmann, and T. F. Schilling. 1995. Stages of embryonic development of the zebrafish. Devel. Dyn. 203: 253-310.

Kilpatrick, T., A. Brown, C. Lai, M. Gassman, M. Goulding, and G. Lemke. 1996. Expression of the Tyro4/M ek4/Cek4 gene specifically marks a subset of embryonic motor neurons and their muscle targets. Mol. Cell. Neurosci. 7: 62-74.

Krull, C., R. Lansford, N. Gale, A. Collazo, C. Marcelle, G. Yancopoulos, S. Fraser, and M. Bronner-Fraser. 1997. Interactions of Eph-related receptors and ligands confer rostrocaudal pattern to trunk neural crest migration. Curr. Biol. 7: 571-580.

M cGlade, J., B. Brunkhorst, D. Anderson, G. M bamalu, J. Settleman, S. Dedhar, M. Rozakis-Adcock, L. Bo Chen, and T. Pawson. 1993. The $\mathrm{N}$-terminal region of GAP regulates cytoskeletal structure and cell adhesion. EMBO J. 12: 30733081.

M acdonald, R., J. Scholes, U. Strahle, C. Brennan, N. Holder, M. Brend, and S. Wilson. 1997. The Pax protein $\mathrm{N}$ oi is required for commisural axon pathway formation in the rostral forebrain. Devel opment 124: 2397-2408.

Meima, L., I. Kljavin, P. Moran, A. Shih, J. Winslow, and I. Carras. 1997a. AL-1 induced growth cone collapse of rat cortical neurons is correlated with REK-7 expression and rearrangement of the actin cytoskeleton. Eur. J. Neurosci. 9: 177-188.

Meima, L., P. Moran, W. Mathews, and I. Caras. 1997b. Lerk2 (ephrin-B1) is a collapsing factor of a subset of cortical growth cones and acts by a mechanism different from AL-1 (ephrin-A5). Mol. Cell. Neurosci. 9: 314-328.

Muller, M., E. Weizsacker, and J. Campos-Ortega. 1996. Expression domains of a zebrafish homologue of the Drosophila pair-rule gene hairy correspond to a primordia of alternating somites. Devel opment 122: 2071-2078.

Palmeirim, I., D. Henrique, D. Ish-Horowicz, and O. Pourquie. 1997. Avian hairy gene expression identifies a molecular clock linked to vertebrate segmentation and somitogenesis. Cell 28: 639-648.

Saga, Y., N. Hata, H. Koseki, and M. Taketo. 1997. Mesp2: A novel mouse gene expressed in the presegmented mesoderm and essential for segmentation initiation. Genes \& Dev. 11: 1827-1839.

Scales, J., R. Winning, C. Renaud, L. Shea, and T. Sargent. 1995. N ovel members of the eph receptor kinase subfamily expressed during Xenopus development. Oncogene 11: 17451752.

Schulte-Merker, S., F. Van Eeden, M.E. Hal pern, C.B. Kimmel, and C. N üsslein-Volhard. 1994. no tail (ntl) is the zebrafish homolog of the mouse $\mathrm{T}$ (Brachyury) gene. Development 124: 1009-1015.

Shanmugalingam, S. and S. Wilson. 1998. Isolation, expression 
and regulation of a zebrafish paraxis homologue. Mech. Dev. (in press).

Smith, A., V. Robinson, K. Patel, and D. Wilkinson. 1997. The EphA4 and EphB1 receptor tyrosine kinases and ephrin-B2 ligand regulate targeted migration of branchial neural crest cells. Curr. Biol. 7: 561-570.

Stein, E., U. Huynh-Do, A. Lane, D. Cerreti, and T. Daniel. 1998. N ck recruitment to Eph receptor, EphB1/ELK, couples ligand activation to c-Jun kinase. J. Biol. Chem. 272: 13031308.

Stern, C. and R. Keynes. 1987. Interactions between somite cells: The formation and maintenance of segment boundaries in the chick embryo. Development 99: 261-272.

Taneja, R., B. Thisse, F. Rijli, C. Thisse, P. Bouillet, P. Dolle, and P. Chambon. 1996. The expression pattern of the mouse receptor tyrosine kinase gene M DK1 is conserved through evolution and requires Hoxa-2 for rhombomere-specific expression in mouse embryos. Devel. Dyn. 177: 397-412.

Thisse, C., B. Thisse, T. Schilling, and J. Postlethwaite. 1994. Structure of the zebrafish snail 1 gene and its expression in wildtype, spadetail and notail mutant embryos. Development 119: 1203-1215.

van Eeden, F., M. Granato, U. Schach, M. Brand, M. FurutaniSeiki, P. Haffter, M. Hammerschmidt, C.-P. Heisenberg, Y.-J. Jiang, D. Kane, R. Kelsh, M. Mullins, J. Odenthal, R. Warga, M. Allende, E. Weinberg, and C. N üsslein-Volhard. 1996. Mutations affecting somite formation and patterning in the zebrafish, Danio rerio. Development 123: 153-164.

Wang, H. and D. Anderson. 1997. Eph family transmembrane ligands can mediate repulsive guidance of trunk neural crest migration and motor axon outgrowth. Neuron 18: 383-396.

Weinberg, E., M. Allende, C. Kelly, A. Abdel hamid, P. Andermann, G. Doerre, D. Grunwald, and B. Riggleman. 1996. Developmental regulation of zebrafish $M y o D$ in wildtype, no tail and spadetail embryos. Development 122: 270-280.

Whitfield, T., M. Granato, F. van Eeden, U. Schach, M. Brand, M. Furutani-Seike, P. Haffter, M. Hammerschmidt, C.-P. Heisenberg, Y.-J. Jiang, D. Kane, R. Kelsh, M. Mullins, J. Odenthal, and C. N üsslein-Volhard. 1996. Mutations affecting development of the zebrafish inner ear and lateral line. Development 123: 241-254.

Winsl ow, J., P. M oran, J. Valverde, A. Shih, J. Yuan, S. Wong, S. Tsai, A. Goddard, W. Henzel, F. Hefti, K. Beck, and I. Caras. 1995. Cloning of AL-1, a ligand for an Eph-related tyrosine kinase receptor involved in axon bundle formation. Neuron 14: 973-981.

Wood, A. and P. Thorogood. 1994. Patterns of cell behaviour underlying somitogenesis and notochord formation in intact vertebrate embryos. Dev. Dyn. 201: 151-167.

Xu, Q., G. Alldus, N. Holder, and D.G. Wilkinson. 1995. Expression of truncated Sek-1 receptor tyrosine kinase disrupts the segmental restriction of gene expression in the Xenopus and zebrafish hindbrain. Devel opment 121: 4005-4016.

Xu, Q., G. Alldus, R. Macdonald, D. Wilkinson, and N. Holder. 1996. Function of the Eph-related receptor tyrosine kinase gene $r$ tk 1 is required for regional specification in the zebrafish forebrain. Nature 381: 319-322. 


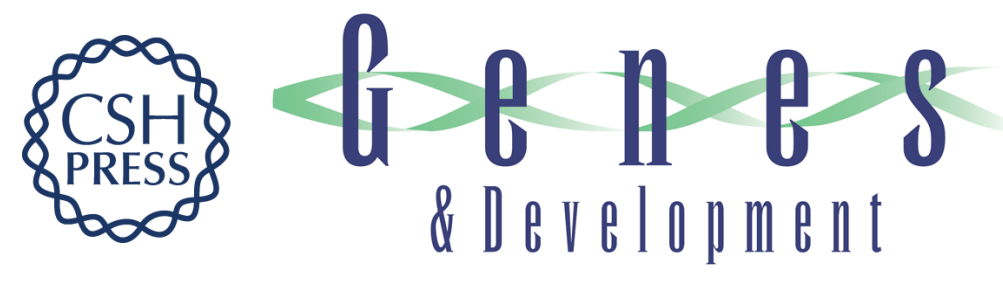

\section{Eph signaling is required for segmentation and differentiation of the somites}

Lindsey Durbin, Caroline Brennan, Kensuke Shiomi, et al.

Genes Dev. 1998, 12:

Access the most recent version at doi:10.1101/gad.12.19.3096

\section{License}

Email Alerting

Service

Receive free email alerts when new articles cite this article - sign up in the box at the top right corner of the article or click here.

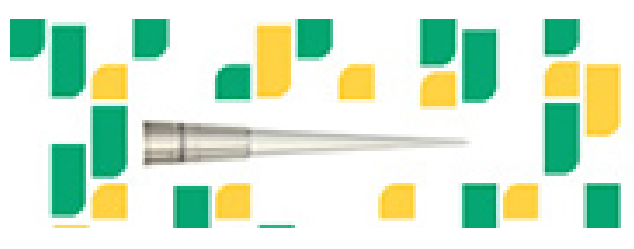

Focused on your science. 